\title{
O filósofo e o místico: da sociedade fechada à ruptura moral
}

Pablo Enrique Abraham Zunino

\section{Resumo}

Ao longo da sua obra, Bergson estabelece uma série de oposições conceituais tais como espaço e duração, matéria e memória, inteligência e instinto. Seguindo essa linha de raciocínio, qual seria a oposição que marca o seu último livro - As duas fontes da moral e da religião? Trata-se da oposição entre a moral fechada e a moral aberta. Por isso, o objetivo deste artigo é investigar em que sentido a "emoção mística" pode proporcionar uma abertura moral capaz de operar uma "conversão da vontade" na alma humana, cujo alcance pode ser notado nas mudanças da sociedade ao longo da história. A linguagem dos místicos, com efeito, traduz em representações a emoção particular da alma que se abre e rompe com a natureza que a encerrava na sociedade fechada. Essa ruptura moral, portanto, pode ser entendida como um desdobramento da tese segundo a qual toda moral é de essência biológica: de um lado, a moral de pressão, que mantém a coesão social à maneira do instinto nas sociedades de insetos; de outro, a moral de aspiração, entendida como um contato místico, isto é, uma coincidência com o impulso vital.

Palavras-chave: Bergson, sociedade, moral, mística. 


\section{Resúmen}

A lo largo de su obra, Bergson establece una serie de oposiciones conceptuales tales como espacio y tiempo, materia y memoria, inteligencia e instinto. Siguiendo esa línea de razonamiento, cuál sería la oposición que marca su último libro - Las dos fuentes de la moral y de la religión? Se trata de la oposición entre la moral cerrada y la moral abierta. Por eso, el objetivo de este artículo es investigar en qué sentido la "emoción mística" puede proporcionar una apertura moral capaz de operar una "conversión de la voluntad" en el alma humana, cuyo alcance se puede notar en los cambios de la sociedad a lo largo de la historia. El lenguaje de los místicos, en efecto, traduce en representaciones la emoción particular del alma que se abre y rompe con la naturaleza que la vincula a la sociedad cerrada. Esta ruptura moral, por lo tanto, se puede entender a partir del argumento según el cual toda moralidad es de esencia biológica: por un lado, la moral de presión, que mantiene la cohesión social del mismo modo que el instinto en las sociedades de insectos; por otro lado, la moral de aspiración, entendida como un contacto místico, es decir, una coincidencia con el impulso vital.

Palabras clave: Bergson, sociedad, moral, mística.

\section{Introdução}

A carência de estudos sobre a filosofia de Bergson no Brasil, entre 1960 e 1990, transparece nas palavras da nota preliminar de Presença e Campo Transcendental (escrito em 1964, mas publicado em 1989), na qual Bento Prado Jr. tenta justificar o fato de não ter publicado o livro imediatamente, mas sim 25 anos depois: "Se meu livro levasse um leitor a reler Bergson [...] eu me consideraria absolvido de meu pecado de juventude". ${ }^{1}$ E no último ensaio de Erro, ilusão, loucura (2004), ele acrescenta: "com [essa frase, eu] queria exprimir um mal-estar efetivamente vivido, a sensação fortemente desagradável de uma banalização crescente da filosofia, de uma escolarização ou tecnificação asfixiantes do pensamento, de que o desinteresse por Bergson seria um dos sintomas". ${ }^{2}$ Isso se agrava quando se trata d'As duas fontes $d a$

\footnotetext{
${ }^{1}$ PRADO Jr., B. Presença e Campo Transcendental: consciência e negatividade na filosofia de Bergson. São Paulo: EDUSP, 1989, p. 9.

2 PRADO Jr., B. Erro, ilusão, loucura: Ensaios. São Paulo: Editora 34, 2004, p. 257.
} 
moral e da religião (1932) ${ }^{3}$, uma vez que essa não é apenas a obra a menos lida de Bergson, mas também a menos interrogada até hoje.

Diferentemente das décadas anteriores (diagnóstico de Bento Prado Jr.), o interesse pela obra de Bergson parece ter revivido nas últimas décadas. $\mathrm{O}$ livro Bergson et la religion (2008), organizado por Ghislain Waterlot ${ }^{4}$, e o livro Lire Bergson (2011), organizado por Frédéric Worms e Camille Riquier ${ }^{5}$, testemunham uma variedade de meditações em torno da obra de Bergson, com as quais, de alguma maneira, este artigo pretende alinhar-se, no sentido de contribuir com a produção em língua portuguesa dos estudos bergsonianos.

\section{A estrutura das Duas Fontes e o estilo de Bergson}

De acordo com F. Worms, o último livro de Bergson pode ser lido de duas maneiras: a leitura horizontal inicia-se no primeiro capítulo e prossegue normalmente, ao passo que a leitura vertical supõe uma estrutura do texto pautada pela oposição entre o "fechado" e o "aberto". ${ }^{6}$ Além disso, essa estrutura toma a forma de uma espiral, visto que retoma os temas do primeiro capítulo, adotando uma nova perspectiva a fim de promover a "abertura" filosófica.

As questões que surgem na primeira volta da espiral (capítulo sobre a moral), podem ser articuladas com os dois capítulos seguintes; sobre a religião estática (função fabuladora da inteligência, superstição religiosa) e a religião dinâmica (aporte do misticismo em estado puro, independente das religiões institucionalizadas e da revelação teológica). Por isso, minha leitura horizontal vai privilegiar o primeiro capítulo (sobre a moral), já que ele pode ser lido de maneira autônoma e, ademais, serve como chave de leitura para os outros dois (sobre a religião); mas vou concluir com algumas considerações sobre o último capítulo (sobre história e política), procedendo assim a uma compreensão mais abrangente da leitura vertical. De certa forma, o último capítulo é uma projeção sobre o que Bergson pensava acerca do futuro; aquilo que hoje, para nós, já é o presente!

\footnotetext{
${ }^{3}$ BERGSON, H. Les deux sources de la morale et de la religion. Paris: PUF, 2008 (Col. Le choc Bergson - édition critique). Doravante citado como DF.

${ }^{4}$ WATERLOT, G (Org.). Bergson et la religion: Nouvelles perspectives sur 'Les deux sources de la morale et de la religion'. Paris: PUF, 2008.

${ }^{5}$ WORMS, F. \& RIQUIER, C. (Orgs.) Lire Bergson. Paris: PUF, 2011.

${ }^{6}$ Cf. WORMS, F. Bergson ou os dois sentidos da vida. São Paulo: Editora UNIFESP, 2011, p. 293-297.
} 
Em relação ao "estilo literário" do autor, devemos reconhecer que ler Bergson não é uma tarefa fácil, apesar dele escrever "na língua de todo mundo", tentando evitar que a filosofia se encerre em um jargão especializado, hermético ao não-especialista. Mas o estilo de Bergson é de uma extrema densidade; ele diz muito em poucas palavras e vai direto ao ponto, sem diluições, deixando de lado todos os materiais de pesquisa. Assim, o autor afasta toda essa decantação preparatória e oferece ao leitor um néctar concentrado. As Duas Fontes, por ser o último livro de Bergson, é sem dúvida o supra-sumo desse néctar e por isso sua leitura não é fácil, já que à sua maneira este livro é, como diz Cortázar, muitos livros. ${ }^{7}$

\section{O contexto histórico das Duas Fontes}

O pano de fundo das Duas fontes é a Primeira guerra mundial (1914-1918). Bergson (1859-1941) morre durante a Segunda Guerra (1939-1945), mas a obra é de 1932 e demorou 25 anos para ser elaborada, após o sucesso de sua obra anterior, A evolução criadora, de 1908. O sucesso de Bergson começou a decair (passou de moda) quando a fenomenologia alemã tomou conta das discussões acadêmicas na França, através das traduções de Hegel, Marx e Husserl. No intervalo de 1960 a 1990, a maior parte dos filósofos não sabia o que pensar de um livro que dava tanta importância à mística; pior ainda, a reivindicava como um método de investigação em filosofia, chegando a afirmar que toda a história humana está estruturada por uma ruptura decisiva levada a cabo pela experiência mística.

Nos anos '80, bem de acordo com o trecho de Bento Prado Jr. lido inicialmente, Waterlot lembra de ter surpreendido vários professores na Universidade, ao declarar seu interesse pela obra de Bergson: esse interesse era, para eles, completamente incompreensível. ${ }^{8}$

De toda maneira, nas Duas Fontes, a significação profunda da mística é considerada independentemente da fé religiosa, das instituições, igrejas e dogmas teológicos que possam ter se desprendido dela sem, contudo, cristalizar seu dinamismo. Trata-se de uma investigação que leva em conta o fundo da natureza humana, pois uma apreensão estática sempre se reduz à perspectiva do momento atual; ao passo que a apreensão dinâmica busca suas origens.

\footnotetext{
${ }^{7}$ Cf. CORTÁZAR, J. Rayuela. Buenos Aires: Sudamericana, 1994.

${ }^{8}$ WATERLOT, G. Op. Cit., p. 4.
} 


\section{A oposição entre "fechado" e "aberto"}

O objetivo do livro nos é revelado, antes de tudo, por seu título: Um título que é uma tese, ou uma afirmação, mesmo se ele implica também uma demonstração: Há duas fontes ou duas espécies de moral e de religião e é muito importante distingui-las. Essa distinção nova será a distinção entre o "fechado" e o "aberto": serão fechadas todas as morais e religiões que se distinguem umas das outras por exclusão mutua, como grupos por fronteiras, o que conduziria, no limite, à guerra; serão abertas as morais e as religiões que se endereçam sem exceção a todo mundo, sem traçar nenhum limite em nenhum espaço.

Não se trata de distinguir entre uma moral e outra, ou entre uma religião e outra, procurando determinar algum tipo de hierarquia, pois em cada moral e em cada religião há uma parte de fechamento e uma parte de abertura. Como o próprio título do livro indica, trata-se de uma tese, que podemos resumir da seguinte maneira: "O que funda a moral tanto como a religião, sob sua forma fechada tanto como aberta, não é a razão, nem a sociedade, o que quer que seja, por exemplo de absolutamente transcendente, mas sim a vida". ${ }^{9}$

Prosseguindo agora com a leitura horizontal, trataremos de compreender a tese do primeiro capítulo do livro: "Toda moral é de essência biológica". Isso já nos permite compreender o elo (a unidade, a continuidade) com o livro precedente, A evolução criadora. Mas, ao mesmo tempo, surge uma dúvida: será que Bergson quer aplicar a filosofia da vida consolidada nesse livro ao problema da moral e da religião ou então (o que muda tudo) trata-se de uma renovação dessa filosofia da vida?

Seja como for, Bergson nos lembra que o homem e sua inteligência são produtos da evolução da vida, do processo evolutivo. ${ }^{10}$ Se os evolucionistas (Darwin, Spencer) ficaram maravilhados com as formas (espécies animais e vegetais), deixaram escapar o processo formador que lhes dera origem.

Assim, é com base no modelo do organismo vivo que Bergson vai pensar a origem da sociedade. Com efeito, a sociedade nos prepara para obedecer através

\footnotetext{
${ }^{9}$ WORMS, F. Bergson ou os dois sentidos da vida. São Paulo: Editora UNIFESP, 2011, p.289.

10 "Somos forçados a reconhecer que o homem é um ser vivo, que a evolução da vida nas suas duas linhas principais, se cumpriu na direção da vida social, que a associação é a forma mais geral da atividade viva uma vez que a vida é organização e que, sendo assim, passamos por transições insensíveis das relações entre células num organismo às relações entre indivíduos na sociedade" (BERGSON. DF, p. 96).
} 
de uma educação que começa no dia em que nascemos e continua ininterrupta em todos os instantes. Daí a nossa disposição, quase natural, para adquirir certos hábitos sociais aos quais obedecemos sem pensar. Na maioria de nossas atividades cotidianas, obedecemos às exigências da sociedade, como se uma força, que Bergson chama "o todo da obrigação", exercesse um peso sobre nós. ${ }^{11}$

O que acontece se tentamos desobedecer? Essa é a primeira questão que um leitor curioso poderia lançar ao texto de Bergson. Em outras palavras, por que obedecemos a leis morais? Os filósofos costumam dizer que se trata de leis racionais. Mas, na verdade, a razão apenas nos convence, nos deixa mais tranqüilos porque nos faz acreditar que estamos no "caminho certo", mesmo contra a nossa vontade (desejos, paixões).

Quando uma criança pergunta aos pais: "por que devo fazer isso?" obtém uma resposta categórica: "porque sim"; a criança pode até mudar de estratégia: "por que não posso ir brincar?”, mas a resposta continua categórica: "porque não". Certamente, há uma "razão" mais complexa (uma cadeia de razões) que permite explicar racionalmente a resposta (justificá-la, na verdade), mas apenas esse "porque sim" ou "porque não" é suficiente para automatizar a obrigação, sobretudo perante a autoridade dos pais.

Notemos, desde logo, que o ser inteligente corre o risco de pensar apenas em si próprio, por isso a inteligência é uma ameaça para a sociedade, ao passo que a disciplina e a obediência favorecem sua coesão. ${ }^{12}$ Uma vez que a atividade da inteligência conduz ao egoísmo, um contra-peso inteligente deverá favorecer o retorno à obediência para estar em regra com a sociedade: essa é a justificativa racional da obrigação: à força das paixões individuais opõe-se à força da pressão coletiva.

Bergson segue um pressuposto metodológico herdado da biologia: a metáfora do elã vital, que agora passa a ser entendida como uma "intenção da natureza". A inteligência e o instinto estariam amalgamados de início; mas desenvolveram-se em duas linhas divergentes de evolução: (1) o instinto nas sociedades de insetos (formigas e abelhas); e (2) a inteligência na sociedade humana. No entanto, a noção de "conjunto" permite compreender porque no homem, apesar da sua inteligência e da escolha individual, o hábito de contrair hábitos (morais) é uma força comparável ao instinto: o "instinto virtual", um halo de instinto que permanece em estado de virtualidade em volta da inteli-

\footnotetext{
${ }^{11}$ BERGSON. DF, p. 17.

${ }^{12} \mathrm{O}$ exemplo da formiga que começa a refletir sobre sua conduta é instrutivo a esse respeito; ela passa por uma reflexão repentina acerca do seu trabalho sem descanso para os outros.
} 
gência. Isso preserva intacto o caráter humano (inteligente) da obrigação. Pois, se a obrigação fosse apenas de natureza instintiva, ela perderia sua especificidade, uma vez que seria pura necessidade. Mas essa necessidade é virtual, isto é, percebida no fundo da obrigação, já que "um ser não se sente obrigado, a não ser que seja livre". ${ }^{13}$

\section{Filosofia, história e sociologia}

Vimos que o contexto histórico das Duas Fontes era a Primeira Guerra, então, "pensemos o que ocorre em tempos de guerra": os indivíduos que compõem uma sociedade são preparados pela educação (serviço militar obrigatório) para uma possível luta com outras sociedades (os estrangeiros). Trata-se evidentemente de uma obrigação moral que visa uma sociedade fechada e não a humanidade inteira, visto que "entre a nação, por maior que ela seja, e a humanidade há toda uma distância, como do finito ao infinito, do fechado ao aberto". ${ }^{14}$ Abre-se aqui o diálogo com a sociologia, particularmente de Durkheim, que vê uma progressão entre o amor à família, à pátria e à humanidade. Bergson vai recusar essa concepção (ilusão intelectualista, fruto de um raciocínio a priori), segundo a qual o homem poderia amar um número crescente de pessoas, como se houvesse uma "dilatação progressiva do sentimento". Na verdade, dirá Bergson, a passagem da sociedade fechada para a sociedade aberta implica uma "ruptura", ou seja, uma diferença de natureza e não de grau. ${ }^{15}$

Vimos também que a "coesão parcial" deve-se à necessidade de uma sociedade fechada defender-se de outra. Haveria uma espécie de "instinto primitivo" que leva a separar "todos os outros homens" daqueles com os quais convivemos. Não se trata, contudo, de chegar à humanidade por "etapas" (família, nação, etc.); é preciso que, de um salto, sejamos transportados para além dela (da humanidade), ultrapassando-a sem tê-la visado como um fim. A idéia de um "amor pela humanidade" não é natural, mas adquirida, e prefigura "outra moral”, isto é, outro gênero de obrigação que se sobrepõe à pressão social. ${ }^{16}$

\footnotetext{
${ }^{13}$ BERGSON. DF, p. 24.

${ }^{14}$ Ibid., p. 27.

${ }^{15}$ Isso significa que o amor à totalidade não supõe a dilatação da alma em virtude da qual passaríamos da família à pátria e desta à humanidade como se fossem três inclinações de um mesmo sentimento que se dilata cada vez mais, abarcando um número crescente de pessoas. Como se a mesma atitude, isto é, o mesmo movimento nos levasse a "agrupar" as três sob o conceito de "amor" e a exprimi-las pela mesma palavra.

${ }^{16}$ Cf. BERGSON. DF, p.28-29.
} 
O segundo momento do capítulo consiste em integrar as duas fontes da moral, isto é, em transpor a passagem da obrigação pura (redução) para a obrigação completa ou mista. Esse método (passagem ao limite) nos permitirá demarcar dois limites, mínimo e máximo, para compreender a diferença de natureza (e não de grau) que há entre a moral fechada e a moral aberta.

1) A moral fechada (pura) se caracteriza pelas formulas impessoais: generalidade, universalidade, aceitação de uma lei. À obrigação natural corresponde uma moral de pressão, que visa à conservação da sociedade fechada. Trata-se de um movimento circular que se produz através do hábito como uma imitação da repetição do instinto. Refere-se ao conjunto de obrigações puras que garante o bem-estar individual e social, comparável ao funcionamento normal da vida (em células de tecidos ou nas sociedades de insetos). Assemelha-se mais ao prazer do que à alegria.

2) A moral aberta (completa) supõe uma personalidade privilegiada que se torna exemplar, um modelo a ser imitado. Essa "outra moral" encarna nesses "homens excepcionais": homens de gênio (artistas, cientistas); filósofos gregos; iluminados (budistas); Santos do cristianismo. ${ }^{17}$ A esse "chamado" dos místicos corresponde a moral de aspiração, que infunde o sentimento de um progresso (marcha à frente, en avant). E essa emoção promove a aceitação e a propagação dessa moral, pois alegria do entusiasmo é mais que o prazer, reabsorve-o nela e não precisa um termo ao qual se dirige (objeto visado). Trata-se de uma certeza, uma convicção que não se submete a nenhuma metafísica, mas, ao contrário, concede a ela seu mais sólido apoio.

Essa grande personalidade moral pode ser um parente (pai, avó), um amigo, um professor, um orientador, alguém que evocamos pelo pensamento. O importante é a relação entre mestre e discípulo que se estabelece quando encontramos um "modelo", isto é, alguém que desperta o "desejo de parecer-se" com ele, uma vez que sentimos um "eco" de suas palavras. ${ }^{18}$

\footnotetext{
17 "Se a primeira moral devia sua força às obrigações pessoais que dela decorrem; na segunda moral, a multiplicidade e a generalidade das máximas se fundem melhor na unidade e na individualidade de um homem" (BERGSON. DF, p. 31).

18 "Pode ser que não escutemos distintamente a voz [das grandes figuras morais]; nem por isso o chamado (l'appel) deixa de ser feito; alguma coisa lhe responde do fundo da nossa alma" (BERGSON. DF, p. 67).
} 


\section{A alma que se abre: um problema para a segunda moral}

A atitude da alma aberta leva à superação da relação inicial entre amigo e inimigo, uma vez que a "humanidade inteira" compreende todos os seres humanos, considerados como "irmãos", sem distinção de raça ou classe social; todos têm uma vocação comum e ninguém é ou pode ser mais do que o outro. ${ }^{19}$

Há portanto uma diferença radical de natureza entre os dois primeiros grupos (família, pátria) e o terceiro, que não é mais um grupo, e sim uma totalidade (humanidade). Família e pátria implicam escolha, exclusão e uma possível incitação à luta, devido à presença de um "objeto" (amigo ou inimigo). Humanidade, por sua vez, remete a uma atitude da alma que é puro movimento; não há atração por nenhum "objeto" nem repulsa pelo "outro", já que a humanidade como um todo é "atravessada" pelo movimento e não "visada" enquanto objeto.

Vimos que a primeira moral opera naturalmente, quase como um instinto; porém, a segunda moral dever ser adquirida, portanto, exige um esforço! Para alguns homens excepcionais foi possível "reabrir o que havia sido fechado e fazer ao menos para si mesmos o que fora impossível à natureza fazer para a humanidade". ${ }^{20}$ Essa "conversão da vontade" é anterior à nova moral; trata-se da emoção, que se prolonga em élan do lado da vontade e em representação explicativa na inteligência. ${ }^{21}$

A esta altura, o leitor poderá suspeitar desses "homens excepcionais": eles não pedem nada, mas a sua existência é um "chamado" para aqueles que desejam segui-los. Como vimos, essa é a essência da "moral de aspiração", por isso homens que servem de exemplo sempre encontram seguidores. Qual seria a força que toma aqui o lugar da pressão social? Para além do instinto e do hábito, haveria uma ação direta sobre o querer, que é a sensibilidade. Nesse sentido, a propulsão exercida pelo sentimento assemelha-se bastante à obrigação. A diferença entre a emoção e a obrigação (moral) é que a ação decorrente da emoção não encontra resistência. Assim como a obrigação, a emoção também impõe alguma coisa, mas ela é consentida, tal como ocorre na "emoção musical": quando ouvimos uma sinfonia, por exemplo, aquilo que a música nos sugere coincide exatamente com o que queremos: parece

\footnotetext{
${ }^{19}$ No limite, esse "amor fraternal" se estende para além (ou aquém) da humanidade, visto que sua forma não depende do seu conteúdo: ele abarca os animais, as plantas, a natureza inteira.

${ }^{20}$ BERGSON. DF, p.56.

${ }^{21}$ Ibid., p.46.
} 
que agimos naturalmente com ela e que somos a cada instante aquilo que a música exprime: alegria, tristeza, etc. Daí a famosa frase de Bergson: a música "não põe esses sentimentos em nós, ela nos põe neles". ${ }^{22}$ Da mesma maneira procedem os iniciadores em moral: eles nos fazem entrar na música junto com eles para que nós a traduzamos em movimento e ação.

Ora, como agimos quando seguimos uma emoção? Sem resistir: "Se a atmosfera da emoção está lá, se eu a respirei, se a emoção me contagia, eu agirei de acordo com ela, serei levado por ela". ${ }^{23}$ Não se trata mais de coerção ou necessidade, mas sim de uma "inclinação à qual não vou querer me resistir". O caráter obrigatório da moral provém dessa pressão que a sociedade exerce sobre o indivíduo, mas no "estado emocional" a pressão é substituída por uma atração, desde que ele tenha a experiência da "emoção original" em virtude da qual se compreende a atração. De fato, só existe uma "única moral", mas ela se estende entre duas extremidades "puras": pressão e aspiração. Entretanto, esses dois pólos nunca aparecem em estado puro, mas sempre misturados numa série de gradações (diferenças de grau). Esses dois limites teóricos assinalam uma "diferença de natureza". ${ }^{24}$

Em resumo, a natureza humana caracteriza-se pela sociabilidade: tal como abelhas e formigas, porém, inteligente! Então, para compensar um possível excesso de individualidade (que põe em risco a coesão do todo), a vida criou um mecanismo quase inteligente: a inteligência mediada pelo hábito, isto é, um "instinto virtual". Assim, a necessidade do todo estabelece a obrigação moral em geral. Não obstante, ao afirmar que não foi a natureza que previu certas regras morais, Bergson reconhece que elas se manifestam através de uma "imprevisível novidade". Nesse sentido, a emoção moral pode ser criadora de novas formas sociais. Assim, a passagem da solidariedade social à fraternidade humana foi possível graças ao esforço dessas "vontades geniais", nas quais o elã da vida opera um rompimento com certa Natureza, mas não com toda a Natureza, e prossegue seu movimento. ${ }^{25}$

\footnotetext{
${ }^{22}$ Ibid., p.36.

${ }^{23}$ Ibid., p.45.

${ }^{24}$ Ibid., p.46-48.

${ }^{25}$ Reminiscências Spinozistas: Para voltar a Natureza Naturante nos separamos da Natureza Naturada. A linguagem dos místicos traduz em representações a emoção particular da alma que se abre e rompe com a natureza que a encerrava na sociedade fechada. A "força de amar a humanidade" vem desse contato com o princípio gerador da espécie humana (elã vital): "Uma alma que não conhece obstáculo material sente-se em coincidência com o princípio mesmo da vida" (BERGSON. DF, p.52).
} 
Isso nos permitiu vislumbrar a possibilidade de uma "sociedade mística" que abarcaria a humanidade inteira, sendo animada por uma vontade comum. Não obstante, tal como a "obrigação pura", essa "aspiração pura" é um limite ideal. Podemos reviver algum grau de misticidade através da "atração virtual" que uma grande figura exerce sobre nós. Porém, quando não temos nenhum interesse pela pessoa, ainda resta a fórmula geral da moralidade aceita pela civilização. Haveria, então, dois tipos de obrigação: (1) a obrigação associada à ordem, caracterizada como um sistema de ordens impessoais (infra intelectual); e (2) o apelo lançado à consciência por certas pessoas: quando desperta a força da emoção (passada, presente ou futura), pode suscitar idéias indefinidamente, visto que é mais do que idéia (supra intelectual).

A vida poderia ter parado nas sociedades fechadas: naquelas compostas por seres inteligentes haveria mais variação que nas instintivas, mas estaríamos bem longe do "sonho de uma transformação radical", isto é, de uma sociedade única que englobasse todos os homens. Talvez essa sociedade não exista nunca! Mas, "de longe em longe", apareceram homens de gênio (artistas, cientistas) que ampliaram os limites da inteligência; o ímpeto vital se manifesta nessas almas privilegiadas (místicos) que visam a humanidade em geral, ao invés de permanecerem nos limites do grupo, acatando a solidariedade estabelecida pela natureza: "O aparecimento de cada uma delas era como a criação de uma nova espécie composta de um indivíduo único". ${ }^{26}$

Se todos pudéssemos enveredar pela via mística, uma mudança global da humanidade seria possível, mas esse não é o caso. Por isso, o aberto precisa instalar-se no fechado (processo de abertura e fechamento da sociedade). É preciso trabalhar a sociedade de dentro, esperando que pouco a pouco as coisas mudem, que a difusão do espírito de abertura seja cada vez mais acentuado.

\section{Mística e libertação}

A aspiração democrática e os ideais de liberdade, igualdade e fraternidade (que fundamentam os direitos humanos) seriam, segundo Bergson, frutos do desenvolvimento e da difusão da mística ao longo da história. A humanidade que sofre com a miséria e a fome é incapaz de ouvir o apelo místico, uma vez que está preocupada com as condições materiais da sua existência. É por isso que "a mística chama a mecânica", apontando outro sentido da

$\overline{{ }^{26} \text { BERGSON. DF, p. } 97 .}$ 
libertação: as condições de possibilidade da libertação. Chegam as máquinas, que aumentam o rendimento da terra e fazem circular seus produtos; chegam as organizações políticas e sociais para provar que as massas não estão condenadas à servidão e à miséria. $\mathrm{O}$ impulso místico sai finalmente dos conventos e mostra toda sua força. ${ }^{27}$

Haveria um propósito de ordem espiritual na origem desse extraordinário sistema de produtividade industrial e técnico ao qual chegamos? Difícil de aceitar: basta olharmos os paises desenvolvidos e o seu modo de vida para perguntarmos onde é que esse desígnio espiritual foi se esconder. Além disso, as religiões presentes na maioria desses paises têm mais a ver com a religião estática do que com a religião dinâmica. Então, o que aconteceu?

Bergson diz que houve um acidente de "aiguillage" (ação de mover as linhas férreas) pelo qual todos se deixaram fascinar pelo desejo e o luxo: "Toda nossa civilização é afrodisíaca". Em vez de garantir a todos o sustento necessário, o industrialismo seduziu o homem com necessidades supérfluas.

\section{A lei da dicotomia e a atualidade das Duas fontes}

Assim como n'A evolução criadora, inteligência e instinto estavam amalgamados na origem e se dividiram em linhas divergentes, intensificando-se cada uma dessas tendências, no homem e no animal, respectivamente; o ascetismo e o conforto provêm de uma mesma tendência. Cada uma dessas tendências corresponde a um dos elementos necessários ao acabamento da humanidade: não há vida espiritual possível e generalizável sem estabilidade material e, inversamente, não há tranqüilidade material sensata sem relação com um objetivo espiritual. Como a humanidade é uma só, essas tendências não ocorrem simultaneamente, mas sucessivamente. Assim, o desenvolvimento histórico da humanidade pode ser visto como uma progressão em espiral: uma fase de ascetismo, depois uma fase de enriquecimento, de desejo e conforto que não pode ignorar completamente a fase anterior que se conserva virtualmente. Cada fase, no entanto, prossegue até o fim de si mesma, isto é, só se detém quando há uma impossibilidade de continuar.

O drama da humanidade se acentua cada vez mais. Cabe perguntar então se saberemos, antes que seja tarde para o nosso meio ambiente e nossas condições climáticas de existência, voltar a uma vida simples graças a qual não nos

${ }^{27}$ Cf. WATERLOT, G. Op. Cit., p. 35-39. 
destruamos a nós mesmos. Alguns chegam a pensar que hoje, quase no fim de 2012, já é tarde demais!

80 anos atrás, Bergson não se deixou intimidar por essas "sirenas de pessimismo", quando viu a Europa levantar os braços ao fascismo e a ciência inventar uma arma secreta capaz de exterminar o adversário na próxima guerra. De lá pra cá, a população sempre crescente têm cada vez menos acesso aos recursos naturais; antigas guerras por território continuam, levando uns a massacrar os outros, novos conflitos bélicos surgem aqui e ali em nome da democracia, mas camuflando a sede capitalista por energias fósseis não renováveis (petróleo).

Enfim, todos esses problemas que aparecem no último capítulo das Duas Fontes, são precisamente os nossos! Será que a mística poderá mudar o rumo dessa tendência produtivista (e consumista), conservando tudo o que ela aportou de positivo para a humanidade? Será que é possível realizar esse progresso em espiral ao qual nos referimos antes?

\section{Conclusão}

A conclusão de Bergson é que nós estamos justamente nessa encruzilhada: o desenvolvimento frenético da tendência que visa ao conforto (e ao luxo) já começou a causar mais danos do que benefícios (excesso de lixo, doenças crônicas e degenerativas provocadas pelo sedentarismo e a má alimentação, agravamento dos distúrbios mentais tais como a depressão e a ansiedade, etc).

Ora, o que fazer enquanto o místico não vem? E se ele nunca vier? Há duas possibilidades: (1) uma é desenvolver a ciência psíquica a fim de conhecer as virtualidades do espírito; o próprio conhecimento nos daria razões para abraçar a causa mística. (2) a outra é o desenvolvimento (muito mais drástico e nem sempre tão eficaz) de uma regulamentação política internacional capaz de deter as constantes ameaças contra os recursos naturais, como as florestas e as fontes de água potável, em muitas áreas já poluídas.

\section{Referências Bibliográficas}

BERGSON, H. Les deux sources de la morale et de la religion. Paris: PUF, 2008 (Col. Le choc Bergson - édition critique) . As duas fontes da moral e da religião. Coimbra: Almedina, 2005 (Trad. de Miguel Serras Pereira; nota de apresentação de Luís Antonio Umbelino). 
. As duas fontes da moral e da religião. Rio de Janeiro: Zahar, 1978 (Trad. De Nathanael Caixeiro). . Matéria e memória: Ensaio sobre a relação do corpo com o espírito. São Paulo: Martins Fontes, 2006. . A evolução criadora. São Paulo: Martins Fontes, 2005. . O Pensamento e o movente. São Paulo: Martins Fontes, 2006.

CORTÁZAR, J. Rayuela. Buenos Aires: Sudamericana, 1994.

DURKHEIM, É. L'éducation morale. Paris: PUF, 1963.

PRADO Jr., B. Presença e Campo Transcendental: consciência e negatividade na filosofia de Bergson. São Paulo: EDUSP, 1989. . Erro, ilusão, loucura: Ensaios. São Paulo: Editora 34, 2004.

WATERLOT, G (Org.). Bergson et la religion : Nouvelles perspectives sur 'Les deux sources de la morale et de la religion'. Paris: PUF, 2008.

WORMS, F. Bergson ou os dois sentidos da vida. São Paulo: Editora UNIFESP, 2011 (Trad. Aristóteles Predebon) . \& RIQ UIER, C. (Orgs.) Lire Bergson. Paris: PUF, 2011.

Pablo Enrique Abraham Zunino

Pós-doutorando USP/FAPESP. Professor do Departamento de Filosofia da Universidade Federal da Bahia. E-mail: zunino@usp.br

Recebido em: 22/11/12 Aprovado em: 23/12/12 